\title{
Value of phenotypic and genotypic identification of Acinetobacter baumannii isolates from two hospitals in Jordan
}

\author{
Mona R. Bustami', \\ Nermen Dakkak', \\ Lauy F. Abu-Qatouseh², \\ Raida Khalil ${ }^{3}$, \\ Khalid Z. Matalka ${ }^{4}$ \\ 1 Faculty of Pharmacy and Medical \\ Sciences, University of Petra, Amman, \\ Jordan \\ 2 Jordan Company for Antibody \\ Production (Monojo), Amman, Jordan \\ 3 Faculty of Science, Philadelphia \\ University, Amman, Jordan. \\ 4 Faculty of Health Sciences, Medical \\ Laboratories, American University of \\ Madaba, Jordan
}

Corresponding author:

\section{Mona R. Bustami}

” mbustami@uop.edu.jo

Keywords: Acinetobacter baumannii, genotyping, multi-drug resistance.

\section{Introduction}

Studies from different parts of the world have demonstrated that Acinetobacter baumannii is a common opportunistic nosocomial pathogen, with increasingly global prevalence [1]. A. baumannii has been found to be responsible for various infections including nosocomial pneumonia, blood infection, urinary tract infection and surgical wound infection especially in patients hospitalized in intensive care unit (ICU) [1-5]. The epidemiology and control of A. baumannii infections in hospitals is a complex issue, since this organism has a great capacity to survive in low-moisture environment coupled with its ability to develop rapidly resistance to antimicrobial agents posing particular risk to hospitalized patients [4-5].

A study by Shehabi and Baadran (1996) revealed that few types of multidrug-resistant Gram-negative bacteria ( $A$. baumanii, Pseudomonas aerugino- 
sa and klebsiella pneumoniae) were commonly associated with Jordanian ICU patients during 1993 [6]. Since then there was increased incidence of A.baumannii infections and colonization in Jordanian hospitals $[5,7]$. In addition, clinical laboratories in Jordan, as other clinical laboratories in other parts of the world, depend mainly upon traditional phenotypic identification methods that relay on biochemical pathways and carbon source utilization [5-7]. Investigators over the years have tried a variety of laboratory improvement tests for identification A.baumannii through appling phenotypic and genotypic techniques [8]. Of such efforts was the use of gas chromatographic analysis [9]. Microlog system, comprising a microtiter plate that tests for the ability of a microorganism to utilize different carbon sources [10], VITEK-2 ID-GNB card (bioMérieux, Hazelwood, MO), and Sherlock microbial identification system which is a fully automated gas chromatographic analytical system that identifies bacteria based on their unique fatty acid profiles [11]. A phenotypic identification of Acinetobacter to the species level was always considered presumptive, and not so accurate since it is useful only for rapid diagnosis of infections $[12,13]$.

Taxonomy of the genus Acinetobacter has revealed 23 validly named species (http://www.bacterio.cict.fr/) and a number of DNA-DNA hybridization groups (genomic species) with provisional designations [14]. However, the identification of Acinetobacter at species level is still erratic and quite variable that hindered progress understanding the pathogenic role of Acinetobacter [15]. Thus, precise identification of Acinetobacter species would be significant in epidemiology, and infection control policies [16]. Since 1986, the taxonomy of the genus Acinetobacter was revised, molecular methods provided the necessary tools to identify Acinetobacter at the species level. Detailed studies of the epidemiology of the different members of this genus became possible using genotyping methods [17]. Molecular methods that have been developed and validated for identification of Acinetobacters include amplified 16S rRNA gene restriction analysis (ARDRA) [18], high-resolution fingerprint analysis by amplified fragment length polymorphism (AFLP) [19], ribotyping [20], tRNA spacer fingerprinting [21], restriction analysis of the 16S-23S rRNA intergenic spacer sequences [22], sequence analysis of the 16S-23S rRNA gene spacer region [12], and sequencing of the $r p o B$ (RNA polymerase $\beta$-subunit) gene and its flanking spacers [23]. Currently, ARDRA and AFLP are the most widely used validated reference methods for species identification of Acinetobacters [18,19]

The tremendous increase in sequencing, lead to partial or nearly complete sequence analysis of the 16S rRNA gene for Acinetobacter classification $[24,25]$. In addition, the 165 and 235 rRNA genes intergenic spacer (ITS) has been suggested to be a good candidate for bacterial species identification [26], since these regions have degrees of low intraspecies variation and high degrees of interspecies divergence $[27,28]$. Therefore, in the present study we have applied 16S-23S rRNA gene intergenic spacer (ITS) sequencing technique to analyze the genotyping of clinical isolates of A.baumannii that were collected from two different hospitals in Jordan, and to correlate their genotypes with phenotypic characters

\section{Materials and Methods}

\section{Bacterial isolates}

A total of 12 isolates of $A$. baumannii were recovered from 12 clinical samples and included in this study. Seven isolates were recovered from ICU patients of the King Hussein Cancer Center (KHCC) in 2006. The rest 5 isolates were recovered from ICU patients of The Jordan University Hospital in 2008. The clinical samples were isolated from 12 patients with different types of infections at two different periods of time. Pure clinical isolates, identified as A. baumannii in the microbiology laboratory of the 
2 hospitals were supplied for conducting this research.

The isolates were subjected to repeat phenotypic identification using a simplified scheme for Acinetobacter spp [29]. In addition to colony morphology, Gram staining reaction and microscopic characterization, the scheme included growth at $37^{\circ} \mathrm{C}, 41^{\circ} \mathrm{C}$, and $44^{\circ} \mathrm{C}$, glucose oxidation, gelatin hydrolysis and Triple sugar iron (TSI) test [30]. Biochemical reactions using API 20 NE system (bioMérieuxVitek, Marcy l'Etoile, France) were also used.

Standard control strains of Pseudomonas aeuroginosa (ATCC 27853) and Escherichia coli (ATCC 25922 strains) were used simultaneously with tested clinical isolates. These controls were used for the purposes of justifying results obtained in several tests including antibiotic susceptibility testing.

\section{Antimicrobial susceptibility testing}

The disk diffusion method on Mueller-Hinton agar was employed to evaluate susceptibility to 19 antimicrobial discs. The antibiotic discs used were purchased from HiMedia, India, contain the following: Gentamycin (G) (10 $\mathrm{\mu g} /$ disc), ciprofloxacin (Cf5) (5 $\mu \mathrm{g} /$ disc), levofloxacin (Le5) (5 $\mu \mathrm{g} /$ disc), cefuroxim (Cxm30) (30 $\mathrm{gg} /$ disc), pipracillin (Prl100) (100 $\mu \mathrm{g} /$ disc), cotrimoxazole (Smx25) (25 $\mu \mathrm{g} /$ disc), cefotaxime (Ctx30) (30 $\mathrm{\mu g} /$ disc), tazobactams

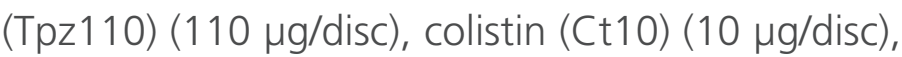
ampicillin (Am10) (10 $\mathrm{gg} /$ disc), tetracyclin (Te30) (30 $\mu \mathrm{g} / \mathrm{disc}$ ), cefoxitin (Fox30) (30 $\mu \mathrm{g} / \mathrm{disc})$, tobramycin (Tb10) $(10 \mu \mathrm{g} / \mathrm{disc})$, cefazolin (Cz30) $(30 \mu \mathrm{g} / \mathrm{disc})$, cefaclore (Cec30) (30 $\mu \mathrm{g} /$ disc), ceftazidime (Ca30)

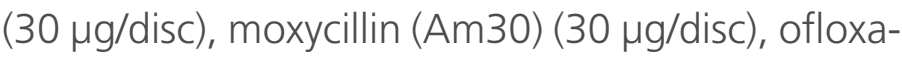
cin (Of5) $(5 \mu \mathrm{g} / \mathrm{disc})$ and imipenem (Ipm10) $(10 \mu \mathrm{g} /$ disc). Zones of inhibition were read and compared with the values of susceptibility interpretive breakpoints issued by the National Committee for Clinical Laboratory Standards (NCCLS, 2013) to determine the degree of susceptibility to each antibiotic tested on each isolate test [31].

\section{Molecular manipulation}

\section{DNA preparation}

A twelve DNA extract of $A$. baumannii isolates were prepared with small scale chromosome extraction using Wizard Genomic DNA purification kit (Promega, USA) in accordance with the manufacturer's instructions.

\section{Amplification of ITS}

The bacterium-specific universal primers 1512F5'GTCGTAACAAGGTAGCCGTA3' and 6R 5 'GGGTTYCCCCRTTCRGAAAT3' where $Y$ is $C$ or $T$ and $R$ is $A$ or $G$ [32] were used to amplify a DNA fragment using Gene Amp PCR system 9700 (Applied Biosystems). The DNA fragment encompassed a small fragment of the 16S rRNA gene region, the ITS, and a small fragment of the $23 \mathrm{~S}$ rRNA gene region. The $5^{\prime}$ end of primer $1512 \mathrm{~F}$ is located at position 1493 of the $16 \mathrm{~S}$ rRNA gene, and the $5^{\prime}$ end of primer $6 \mathrm{R}$ is located at position 108 downstream of the $5^{\prime}$ end of the 235 rRNA gene (Escherichia coli numbering).

Using PCR reaction mixtures of a total volume of $50 \mu \mathrm{l}$ were prepared for all samples as follow: $5 \mu \mathrm{l}$ of each primer, $2.5 \mu \mathrm{L}$ of DNA template, $25 \mu \mathrm{L}$ of Go Taq Green Master Mix (Promega, USA), and 2 $X, 12.5 \mu$ of Nuclease-free water (up to $50 \mu$ total volume). PCR was carried out in a with an initial denaturation step at $94^{\circ} \mathrm{C}$ for 2 minutes followed by 35 cycles of denaturation $\left(94^{\circ} \mathrm{C}\right.$ for 1 minute), annealing $\left(62^{\circ} \mathrm{C}\right.$ for 1 minute) and extension $\left(72^{\circ} \mathrm{C}\right.$ for 1 minute). The reaction was terminated with an extended elongation step ( $72{ }^{\circ} \mathrm{C}$ for 7 minutes). PCR products were purified using a Wizard SV gel and PCR clean-up System (Promega, USA). The amplified fragments obtained were electrophoretically separated in $2 \%$ agarose gels.

\section{Identification of $\boldsymbol{A}$. baumannii isolates by ITS sequencing}

DNA sequencing of the ITS of the twelve clinical isolates that were identified as $A$. baumannii with the API 20 NE system (bioMérieuxVitek) was car- 
ried out at the automated DNA sequencing facility using the TaqDyeDeoxiTerminator Cycle Sequencing Kit, and the sequence was analyzed in an automatic DNA sequencer in Korea (373A; Applied Biosystems). During analysis of the sequences obtained, the portions of the 16S and 23S rRNA gene regions were removed from the sequence data to obtain the exact ITS sequences. ITS DNA sequences of the isolates along with sequences of known Acinetobacter geno-species prototype strains retrieved from the GeneBank were aligned using molecular evolutionary genetic analysis programs (Mega 5.10).

\section{Identification of the isolates by ARDRA}

The ARDRA method was carried out as described previously $[18,33]$. Briefly, the amplified $16 \mathrm{~S}$ rRNA gene was obtained by Gene Amp PCR system 9700 (Applied Biosystems). The sequences of the primers were 59TGGCTCAGATTGAAC GCTGGCGGC39 (59 end of the 16S rRNA gene) and 59TACCTTGTTACGA CTTCACCCCA39 (39 end of the 16S rRNA gene). Amplification was performed under the following conditions: initial denaturation step for 6 min at $94^{\circ} \mathrm{C}$ followed by 35 cycles of denaturation $\left(94^{\circ} \mathrm{C}\right.$ for $\left.45 \mathrm{~s}\right)$, annealing $\left(60^{\circ} \mathrm{C}\right.$ for $\left.45 \mathrm{~s}\right)$, and extension $\left(72^{\circ} \mathrm{C}\right.$ for $\left.1 \mathrm{~min}\right)$. The reaction was terminated with an extended elongation step $\left(72^{\circ} \mathrm{C}\right.$ for $7 \mathrm{~min}$ ). Separate aliquots were digested with four restriction endonucleases (fol, Alul, Rsal and Mspl (Promega, USA). The fragments obtained by digestion with each enzyme were electrophoretically separated in $2.5 \%$ agarose gels. Species identification was done by comparing the profiles consisting of the combination of restriction patterns generated with the different enzymes to those of a library of profiles of strains of described named and unnamed species [18,33] (http://allserv.rug. ac.be/ mvaneech/ARDRA/Acinetobacter.html).

\section{Results}

\section{Bacterial isolates}

The biocharacteristics of the 12 clinical isolates are shown in Table 1. Re-identification of the 12 clinical isolates using presumptive method for phenotypic characterization of Acinetobacter spp by API 20 NE system showed that all isolates belonged to $A$. baumannii with confidence levels $>90 \%$.

\section{Antibiotic susceptibility testing}

A. baumannii isolates revealed $100 \%$ resistance to the following investigated antibiotics ( Gentamycin, cefuroxim, cotrimoxazole, cefotaxime, tazobactams, ampicillin, tetracyclin, cefoxitin, cefaclore, ceftazidime, amoxycillin, cefazolin and pipracillin, cirofloxacin, tobramycin, oflacacin, and levofloxacin, while all these were susceptible to colistin and imipenem.

\section{Amplification of ITS fragments}

The ITS fragments of $12 \mathrm{~A}$. baumannii (genomic) species were amplified by PCR with primers $1512 \mathrm{~F}$ and $6 R$. A single amplification product indicated a single amplicon of very constant length was observed for all isolates, and all the ITS fragments were 607bp which referred to $A$. baumannii (Figure 1). These results confirm the close similarity between all 12 strains obtained from two different hospitals.

\section{Identification of clinical A. baumannii by ITS DNA gene sequencing}

The twelve sequencing analysis revealed that the 5 ' end of the ITS sequences were ACGAAAGATT, whereas the 3' end sequence were GGGGTTGTAT which confirmed the identification of $A$. baumannii. The BLAST program in National Center for Biotechnology Information was used to align the 16S235 rRNA intergenic spacer sequence of the new isolates with previously published sequences in the public database. ITS sequence analysis showed that 
Table1. Phenotypic Characteristics and Antibiogram of the twelve clinical isolates of Acinetobacter baumannii

\begin{tabular}{|c|c|c|c|c|c|c|c|c|c|c|c|c|}
\hline \multirow{2}{*}{$\begin{array}{l}\text { Patients' } \\
\text { Features }\end{array}$} & \multicolumn{12}{|c|}{ Sample No. } \\
\hline & 1 & 2 & 3 & 4 & 5 & 6 & 7 & 8 & 9 & 10 & 11 & 12 \\
\hline Gender/age & $\mathrm{F} / 51$ & $\mathrm{~F} / 70$ & $\mathrm{M} / 62$ & $\mathrm{M} / 42$ & $\mathrm{M} / 47$ & $\mathrm{~F} / 35$ & $\mathrm{~F} / 35$ & $\mathrm{~F} / 78$ & $\mathrm{~F} / 14$ & $\mathrm{~F} /<1$ & $M / 58$ & $\mathrm{M} / 34$ \\
\hline $\begin{array}{l}\text { Sample } \\
\text { source }\end{array}$ & wound & wound & sputum & sputum & wound & wound & wound & blood & wound & CSF & wound & blood \\
\hline \multicolumn{13}{|c|}{$\begin{array}{l}\text { Phenotypic } \\
\text { Characteristics }\end{array}$} \\
\hline $\begin{array}{l}\text { Gram } \\
\text { staining }\end{array}$ & \multicolumn{12}{|c|}{ Gram-negative coccobaccilli } \\
\hline $\begin{array}{c}\text { Growth at } \\
37^{\circ} \mathrm{C}, 42^{\circ} \mathrm{C} \\
44^{\circ} \mathrm{C}\end{array}$ & \multicolumn{12}{|c|}{ Heavy growth after 24 hour of incubation at $37^{\circ} \mathrm{C}, 42^{\circ} \mathrm{C}$ and $44^{\circ} \mathrm{C}$} \\
\hline Catalase & \multicolumn{12}{|c|}{ All isolates were catalase +} \\
\hline Oxidase & \multicolumn{12}{|c|}{ All isolates were oxidase - } \\
\hline TSI & \multicolumn{12}{|c|}{ Alkaline/ Alkaline } \\
\hline $\begin{array}{c}\text { Glucose } \\
\text { oxidation* }\end{array}$ & \multicolumn{12}{|c|}{ All isolates were Glucose oxidizers } \\
\hline $\begin{array}{l}\text { Gelatin } \\
\text { hydrolysis }\end{array}$ & \multicolumn{12}{|c|}{ All isolates liquefied gelatin } \\
\hline API 20NE & \multicolumn{12}{|c|}{ "Excellent" identification for Acinetobacter baumannii with $94.8 \%}$. \\
\hline
\end{tabular}

\begin{tabular}{|c|l}
\hline \multicolumn{2}{|c|}{ Antibiogram } \\
\hline R & $\begin{array}{l}\text { Gentamycin, Cefuroxim, Cotrimoxazole, Cefotaxime, Tazobactams, Ampicillin, Tetracyclin, Cefoxitin, Cefaclore, } \\
\text { Ceftazidime, Amoxycillin, Cefazolin, Pipracillin, Cirofloxacin, Tobramycin, Oflacacin, Levofloxacin }\end{array}$ \\
\hline $\mathrm{S}$ & Colistin , Imipenem
\end{tabular}

*Acinetobacter isolates were tested for their abilities to oxidize glucose in Hugh and Leifson's medium

there was a strong similarity (86-88\%) between the isolates and representative strains of the genus Acinetobacter in gene bank using the blast tool.

\section{Identification of clinical isolates by ARDRA}

The $16 \mathrm{~S}$ rRNA gene (16S rDNA) was enzymatically amplified for all the 12 isolates belonging to the $A$. baumannii, and the amplicon was restricted independently with the enzymes Cfol, Alul, Rsal and Mspl. Restriction patterns were analyzed by 2.5\% agarose gel electrophoresis which represents digestion pattern for 3 isolates, giving an overview of all of the patterns observed and all 12 isolates showed identical patterns for all restriction enzymes' digest (Figure 2). The pattern interpretation deduced that the 12 isolates are Acinetobacter baumannii using band analysis library at (http:// allserv.rug.ac.be/mvaneech/ARDRA/Acinetobacter. html).

\section{Discussion}

This study describes and compares the molecular relationships and antibiograms of $A$. baumannii 


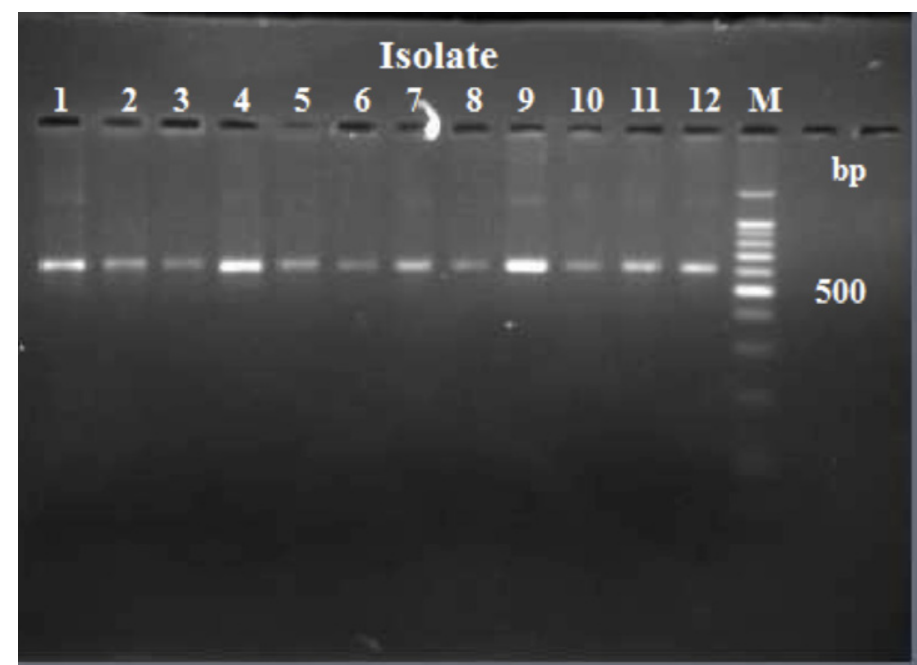

Figure 1. Amplification of Acinetobacter baumannii with primers $1512 \mathrm{~F}$ and $6 \mathrm{R}$ and separation of the PCR products by $2 \%$ agarose gel electrophoresis. Lanes: M, 100-bp DNA ladder.

isolates from patients hospitalized in two intensive care units of 2 major hospitals in Amman, Jordan. The phenotypic characterization results indicated that all isolates were belonging to $A$. baumannii. This preliminary result showed apparently that these $A$. baumannii isolates might be belonged to same clone. While genus-level characterization is usually sufficient for clinical diagnostic purposes, but it is not enough to prove the common source of isolates or their true genomic relationship. In addition, phenotypic methods are not enough to track transmission of isolates in hospital or help to understand the mechanisms of Acinetobacter infections. The original sources of the infecting organisms, their clone similarity, and geographical spread are considered an important requirements for the development of appropriate infection control measures.

Therefore, 16S-23S rRNA gene intergenic spacer (ITS) region as a genotypic method was performed for the genomic identification of these isolates. The results of this study demonstrated a high degree of conservation of both the ITS length and the ITS se-

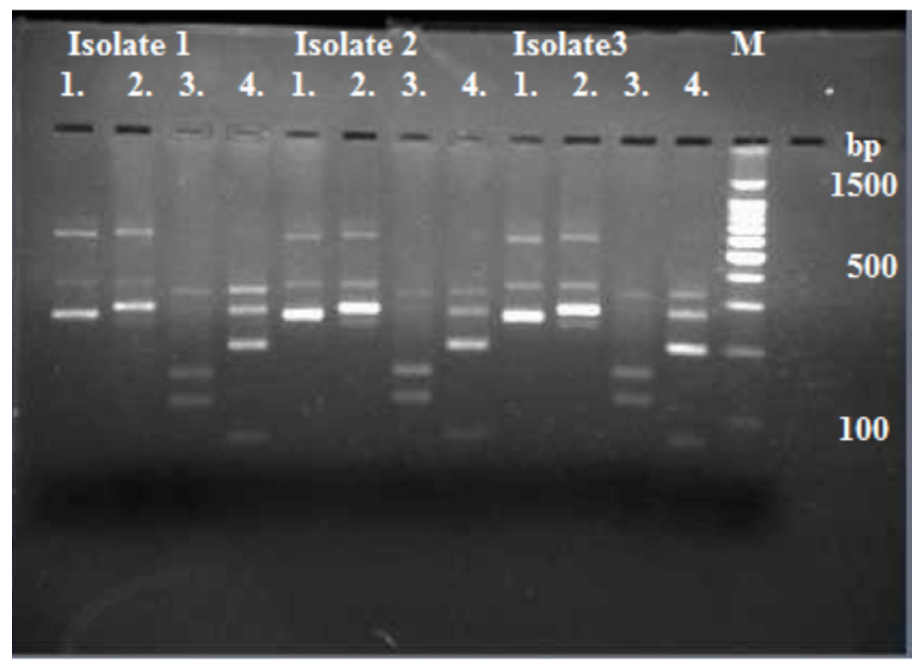

Figure 2. Restriction patterns of the amplification products obtained from 3 isolates amplicon of Acinetobacter baumannii. A total of 8 $\mathrm{ml}$ of the postamplification reaction mixture was digested with 1 . Rsal, 2. Cfol, 3. Alul, 4. Mspl and run in a 2.5\% agarose gel. Lane designations indicate restriction, patterns. Lane M, 100-bpair ladder molecular weight marker.

quence of the twelve isolates which are a common feature in all species of Acinetobacter spp [12]. Restriction analysis of the amplified 165 rRNA gene (16S rDNA) was performed for more specific differentiation. It was observed that multiple ARDRA profiles may occur among different strains of the same species [12]. However, the conserved restriction enzyme analysis revealed that the 12 clinical isolates belonged to the same genomic group of Acinetobacter baumannii complex.

The application of ARDRA for the identification of Acinetobacter species has several advantages over phenotypic identification. ARDRA considered rapid and reliable and universally applicable method for identification of most of the Acinetobacter genomic species, thus contribute to better understanding of the clinical importance and epidemiology of this organism [17]. Summation of all phenotypic, antibiogram, and genotyping results suggested that there might be a common origin of infection in both JUH and KHCC. This study demonstrated the same genotype causing infection /colonization at the two major hospitals in Amman. The potential 
sources of infection might be a common environmental reservoir that spread the organism such as water supply, ventilator, hospital staff, intravenous lines or monitoring devices, surgical drains or indwelling urinary catheters. To investigate the potential source of Acinetobacter nosocomial infection in hospital, samples should be taken from all those possible sources and patients for investing the genotypes of isolates by other advance genetic methods. An important drawback of this study is a lack of any tracing information for the movement of patients within and outside the hospital and no tracing information on visitors to the infected patients. However, a recent study carried at the JUH, found that $A$. baumannii isolates from hospital environmental and patients' respiratory tract sources have a common biological characteristics including much similar multidrug resistance patterns [5].

In conclusion, this study suggests that all $12 \mathrm{~A}$. baumannii isolates have similar phenotypic and genotypic characteristics, although $A$. baumannii complex might be phenotypically homogeneous but genotypically heterogeneous.

\section{Acknowledgment}

We are grateful to Prof. Asem Shehabi and Dr. Mustafa Saad from KHCC Bacteriology laboratories for providing us with the clinical samples. We also extend our thanks to Mrs. Ibtisam Jaber for her technical assistance. This study was supported by grant from the Deanship of Research at University of Petra, Amman, Jordan

\section{References}

1. Chiang T, Pastagia M, Huang DB. Bacteremia caused by Acinetobacter baumannii: epidemiologic features, antimicrobial susceptibility, and outcomes. Adv Infect Dis 2014;4: 66-71.

2. Peleg AY, Seifert H, Paterson DL. Acinetobacter baumannii: emergence of a successful pathogen. Clin Microbiol Rev 2008; 21:538-582.

3. Vincent JL, Rello J, Marshall J, Silva E, Anzueto, Martin ACD, et al. International study of the prevalence and outcomes of infection in intensive care units. JAMA 2009; 302:2323-2329

4. Park KH, Shin JH, Lee SY, Kim SH, Jang MO, Kang SJ. The clinical characteristics, Carbapenem resistance, and outcome of Acinetobacter bacteremia according to Genospecies. PLOS One 2013; 8: 65026.

5. Obeidat N, Jawdat F, Al-Bakri AG, Shehabi AA. Major biologic characteristics of Acinetobacter baumannii isolates from hospital environmental and patients' respiratory tract sources. Am J Infect Control 2014; 42:401-404.

6. Shehabi AA, Baadran I. Microbial infection and antibiotic resistance patterns among Jordanian intensive care patients. East Mediterr Health J 1996; 2: 515-520.

7. Al-Dabaibah N, Obeidat NM , Shehabi AA. Epidemiology features of Acinetobacter baumannii colonizing respiratory tracts of ICU patients. IAJAA 2012; 2:1-7.

8. Tang YW, Ellis N, Hopkins, KM Smith HD, Dodge ED, Persing $\mathrm{DH}$. Comparison of phenotypic and genotypic techniques for identification of unusual aerobic pathogenic gram-negative bacilli. J Clin Microbiol 1998; 36:3674-3679.

9. Abel K, de Schmertzing $H$, Peterson Jl. Classification of microorganisms by analysis of chemical composition. J Bacteriol. 1963; 85: 1039-1044.

10. Miller JM, Rhoden DL. Preliminary evaluation of Biolog, a carbon source utilization method for bacterial identification. J Clin Microbiol 1991; 29: 1143-1147.

11. Osterhout GJ, Shull VH, Dick JD. Identification of clinical isolates of gram-negative non fermentative bacteria by an automated cellular fatty acid identification system. J Clin Microbiol 1991; 29: 1822-1830.

12. Chang CH, Wei L, Dijkshoorn L, Vaneechoutte M, Tang C, Chang CT. Species level identification of isolates of the Acinetobacter calcoaceticu - Acinetobacter baumannii complex by sequence analysis of the 16S-23 rRNA gene spacer region .J Clin Microbiol 2005; 43: 1632-1639.

13. Nemec A, Krizova L, Maixnerova M, Van Der Reijden TJ, Deschaght $P$, et al. Genotypic and phenotypic characterization of the Acinetobacter calcoaceticus-Acinetobacte rbaumannii complex with the proposal of Acinetobacter pittii sp. nov. (formerly Acinetobacter genomic species 3) and Acinetobacter nosocomialis sp. nov. (formerly Acinetobacter genomic species 13TU). Res Microbiol 2011; 162: 393-404.

14. Touchon M, Cury J, Yoon E, Krizova L, Cerqueira GC, et al. The genomic diversification of the whole Acinetobacter genus: origins, mechanisms, and consequences. Genome Biol Evol 2014; 6: 2866-2882.

15. Ahmad SS, Alp E. Genotyping methods for monitoring the epidemic evolution of A. baumannii strains. J Infect Dev 2015; 9:347-354

16. Ecker JA, Massire C, Hall TA, Ranken R, Pennella TD et al. Identification of Acinetobacter species and genotyping of Acinetobacter baumannii by multilocus PCR and Mass Spectrometry. J Clin Microbiol 2006; 44: 2921-2932.

17. Vaneechoutte M, Dijkshoorn L, Tjernberg I, Elaichouni A, de Vos $P$, et al. Identification of Acinetobacter genomic species by amplified ribosomal DNA restriction analysis. J Clin Microbiol 1995; 33:11-15. 
18. Dijkshoorn L, Van Harsselaar B, Tjernberg I, Bouvet PJ, Vaneechoutte M. Evaluation of amplified ribosomal DNA restriction analysis for identification of Acinetobacter genomic species. Syst Appl Microbiol 1998; 21:33-39.

19. Janssen $P$, Maquelin K, Coopman R, Tjernberg I, Bouvet $P$, Kersters K, Dijkshoorn L. Discrimination of Acinetobacter genomic species by AFLP fingerprinting. Int J Syst Bacteriol 1997; 47:11791187.

20. Gerner-Smidt P. Ribotyping of the Acinetobacter calcoaceticusAcinetobacter baumannii complex. J. Clin. Microbiol 1992; 30:2680-2685.

21. Ehrenstein B, Bernards AT, Dijkshoorn L, Gerner-Smidt P, Towner $\mathrm{KJ}$, et al. Acinetobacter species identification by using tRNA spacer fingerprinting. J Clin Microbiol 1996; 34(10):2414-2420.

22. Dolzani L, Tonin E, Lagatolla C, Prandin L, Monti-Bragadin C. Identification of Acinetobacter isolates in the A. calcoaceticus-A. baumannii complex by restriction analysis of the 16S-23S rRNA intergenic-spacer sequences. J Clin Microbiol 1995; 33(5):11081113.

23. La Scola B, Gundi VA, Khamis A, Raoult D. Sequencing of the rpoB gene and flanking spacers for molecular identification of Acinetobacter species. J Clin Microbiol 2006; 44:827-832.

24. Howard A, O'Donoghue M, Feeney A, Sleator RD. Acinetobacter baumannii: An emerging opportunistic pathogen. Virulence 2012; 3: 243-250.

25. Ibrahim AP, Gerner-Smidt P, Liesack W. Phylogenetic relationship of the twenty-one DNA groups of the genus Acinetobacter as revealed by 165 ribosomal DNA sequence analysis. Int. J. Syst. Bacteriol 1997; 47:837-841.

26. Chiang MC, Kuo SC, Chen $Y C$, Lee $Y T$, Chen TL, Fung CP. Polymerase chain reaction assay for the detection of Acinetobacter baumannii in endotracheal aspirates from patients in the intensive care unit. J Microbiol Immunol Infect 2011; 44: 106-110.

27.Whiley RA, Duke B, Hardie JM, Hall LMC. Heterogeneity among 16S-23S rRNA intergenic spacers of species within the "Streptococcus milleri group". Microbiology 1995;141:14611467.

28. Chen CC, Teng LJ, Chang TC. Identification of clinically relevant Viridans Streptococci by sequence analysis of the 16S-23S rDNA spacer region. J Clin Microbiol 2004; 42:2651-2657.

29. Bouvet PJM, Grimont PAD. Identification and biotyping of clinical isolates of Acinetobacter. Annales de I'Institut Pasteur / Microbiologie 1987; 138(5):569-578.

30. Bouvet PJM, Jeanjean S. Delineation of new proteolytic genomic species in the genus Acinetobacter. Res Microbiol 1989; 140 : 291-299.

31. Clinical Laboratory and Standards Institute (CLSI,2012), Method for dilution antimicrobial susceptibity tests for bacteria that grow aerobically. CLSI, Villanova, PA, USA.
32. Relman DA. Universal bacterial $16 S$ rRNA amplification and sequencing. In: Persing D H, Smith TF, Tenover FC, White TJ, editors. Diagnostic molecular microbiology: Principles and Applications. Washington, D.C.: Am Soc Microbiol 1993. pp. 489-495.

33. Nemec, A., L. Dijkshoorn, and P. Jezek. Recognition of two novel phenons of the genus Acinetobacter among non-glucoseacidifying isolates from human specimens. J. Clin. Microbiol 2000; 38:3937-3941.

\section{Comment on this article:}

\section{(f) $B$ in $8+\mathbf{S} P$}

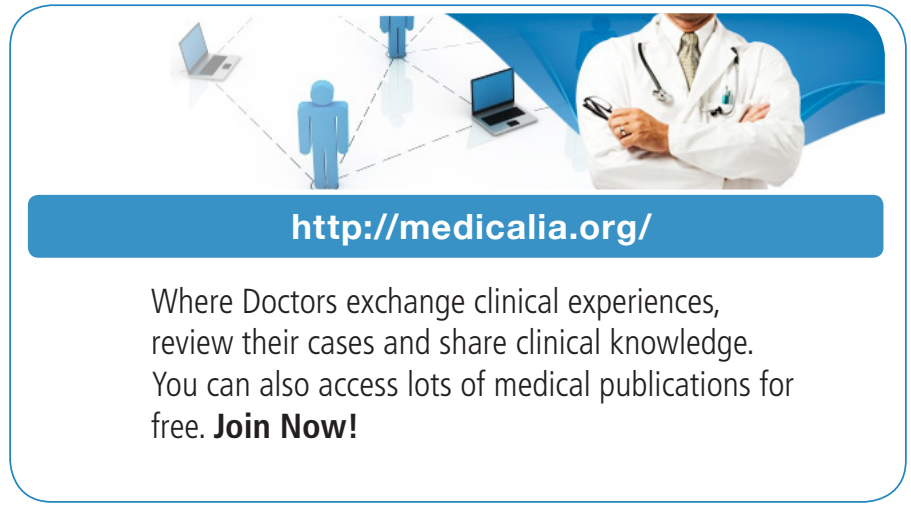

\section{Publish with iMedPub}

http://www.imed.pub

The Journal is an open access peer-reviewed journal that publishes scientific papers about all aspects of antimicrobials. The journal will publish original research articles, reviews, brief reports and case reports dealing with basic and clinical antibacterial agents, antiviral, antiprotozoals, antituberculuous, antifungal and antihelminthes agents. All manuscripts must be prepared in English, and are subject to a rigorous and fair peer-review process. Accepted papers will immediately appear online.

The journal aims to advance the knowledge, attitude and the research of chemotherapy in the Arabic world in cooperation with international, national scientific and public societies as well as research centers with similar aims and objectives. 